\title{
CONTINUOUS IMPROVEMENT IN TQM
}

\author{
Jawaher Abdullah Saeed AIQahtani ${ }^{1}$, Enaas mushabab Turky ${ }^{2}$, Abdullah Saad AL- \\ Malaise AL-Ghamdi ${ }^{3}$ \\ 1,2,3 Faculty of Computing and Information Technology, \\ Department of Information Systems \\ King Abdulaziz University, Kingdom of Saudi Arabia \\ aalmalaise@kau.edu.sa
}

\begin{abstract}
The Field of TQM Total quality Management seeks to have all the functions in an organization integrated. IT has been a favorite subject of research specially in the areas of Service and production. The studies aimed at addressing the topic of continual improvement in the sphere of TQM and its applications. Different researchers had their individual approaches and their researches concluded differently. With this paper we attempt to do a comparative analysis of the research work done by various people in the areas of TQM, its aims, principles, models and applications.
\end{abstract}

Index Terms- E-Learning Framework, Kirkpatrick models, Baldrige Model

\section{Council for Innovative Research}

Peer Review Research Publishing System

Journal: International Journal of Management \& Information Technology

Vol. 9, No. 3

editor@cirworld.com

www.cirworld.com, member.cirworld.com 


\section{INTRODUCTION}

Finding theories and models for continual improvement in the field of Total Quality Management is one of the favorite tpic of researchers. In this paper we would attempt to analyze some of the work published, to establish that it is the common principles and basis that would enable achieving of the all the aims and targets. The terms used by the researchers may be different but the basis of the results is the same.

\section{RESEARCH WORKS COMPARISON}

\subsection{A comparison of "Kirkpatrick \& EFQM models of TQM e-learning" - Jeanne Schreurs (1), Hasselet} University,Belgium and "Application of TQM in Academics" Dheeraj Mehortra (2):-

"A famous quality Management tool" is what EFQM Excellence model has been identified by Jeanne Schreurs as, and it has been termed as being useful in the quality management of e-learning. The development of the stakeholder model of e-learning has been described by her and how she developed the Kirkpatrick - European Foundation for Quality Management SelfAssessment Frame-work after presenting the Kirkpatrick e-Learning model.

In order to improve quality management and to support its application in e-learning, the concept of quality was defined by Jeanne Schreurs. She also attempted to discover the means of assessing quality and embedding it in the current procedures of operation followed by organizations of learning. She was successful in determining the most suitable system of quality management that can be implemented in such organization. The e focus of the paper was on how to assess quality.

She argued for becoming the best learning organization the only way was to balance and satisfy all stakeholders' needs. While Dheeraj Mehrotra (2010) asserts the same topic about application of TQM in academics. In his paper he describes TQM to have 4 pillars.<Done>

Under the principle of "Synergistic relationships" which is the first of his principles, he states that focusing on the supplier and the customer is very essential, this is in sync with the concept of stakeholders described by Schereurs in her research - the importance of collaboration and teamwork is also emphasized.

The second principle of Dheeraj Mhrotra corresponds to Schereurs' concept of achieving excellence by improvement, innovation and continuous learning. The principle is named as "Continuous improvement and selfevaluation", this principle also highlights the process of continuously improving the capabilities of an individual along with the TQM approach of win-win situations.

Mehrotra believes in the Deming rule of "no human being should ever evaluate another human being" along with use of evaluating oneself as a means of continual improvement as his third principle, with corresponds with Schereurs revealing the EFQM model to be used on an organizational level in the form of a quality assessment tool. She asserted that tool can be used in enabling the organization in identifying its weakness and strength, the tool can also be used in the form of a benchmark amongst different organizations, while identifying the improvement areas.

Leadership is the 4th principle proposed by Mehrotra for employing TQM in the field of academics, according to him the success responsibility of top-management is quite essential; whereas on the other hand Schereurs presents processes, resources, Policy \& strategy and also Leadership as the essential ingredients for implementing the EFQM Model at any organization build around Elearning. It was suggested by her that the satisfaction of the people, clients and the impact of the leaders on the society and the success of company would decide the effectiveness of result.

The Evaluation model of Kirkpatrick was discussed by Schereurs, in order to establish it as a model of selfevaluation. She argued that the model consisted of 4 quality evaluation levels. After that the e-learning EFQM TQ Model was merged with that of Kirkpatrick to arrive at the "Kirkpatrick-EFQM self-assessment framework". This framework could be utilized by the stakeholders in a company for assessing the e-leaning's quality level.

We can thus deduce by comparing the two research works that if the 4 principle of introduction of TQM to academics were followed we can assure the presence of new models of assessment and ensuring Total Quality Management. The principles would also assure the continual progress of the e-learning as well as traditional learning.

\subsection{Comparison of "TQM Principles" - Khurram Hashmi, (3) and "Baldrige Model" - Bill Denney and Denis Leonard (4):-}

Looking at the middle of the $20^{\text {th }}$ Century we find the "Baldrige Model" under this model all the strategic flows started from the leaders and they ended with the result. While observing the Fig 1 below we can conclude that, for any organization to make major improvements in itself it is quintessential for the senior leaders to have the maximum possible engagement in that change. The senior leaders would be able to bring in a major reaction across the organization and thus be able to achieve continual progress. 


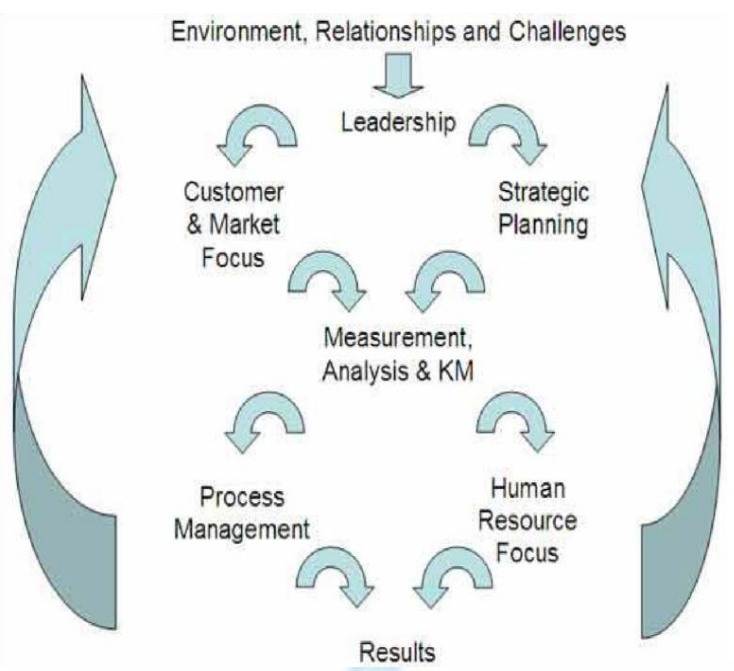

Fig 1. Leadership flow by Baldrige

We can clearly see the in Fig 2 that under the Baldrige model the result Triad (Results, Processes and staff) is directly linked with the leadership's triad (customer focus, planning, and leadership).It also depicts the effect of Measurement on both Leadership \& Results. It also illustrates the placing of each piece with respect to the other and highlights the fact that the criterion need to be looked through the system's perspective and how the entire organizations can be penetrated by them.

The Baldrige model's education Benchmarks as asserted by by "Bill Denney and Denis Leonard" in their paper titled "Aspects of Baldrige - Valuable perspectives" that was published in the "Quality Digest's Quality Insider(Jul, 2007), were a group of question related to 7 essential aspect being able to manage and perform in the form of an organization:

a) Results

b) Workforce focus

c) Operations focus

d) Knowledge management and Measurement, analysis.

e) Customer focus

f) Strategic planning

g) and Leadership

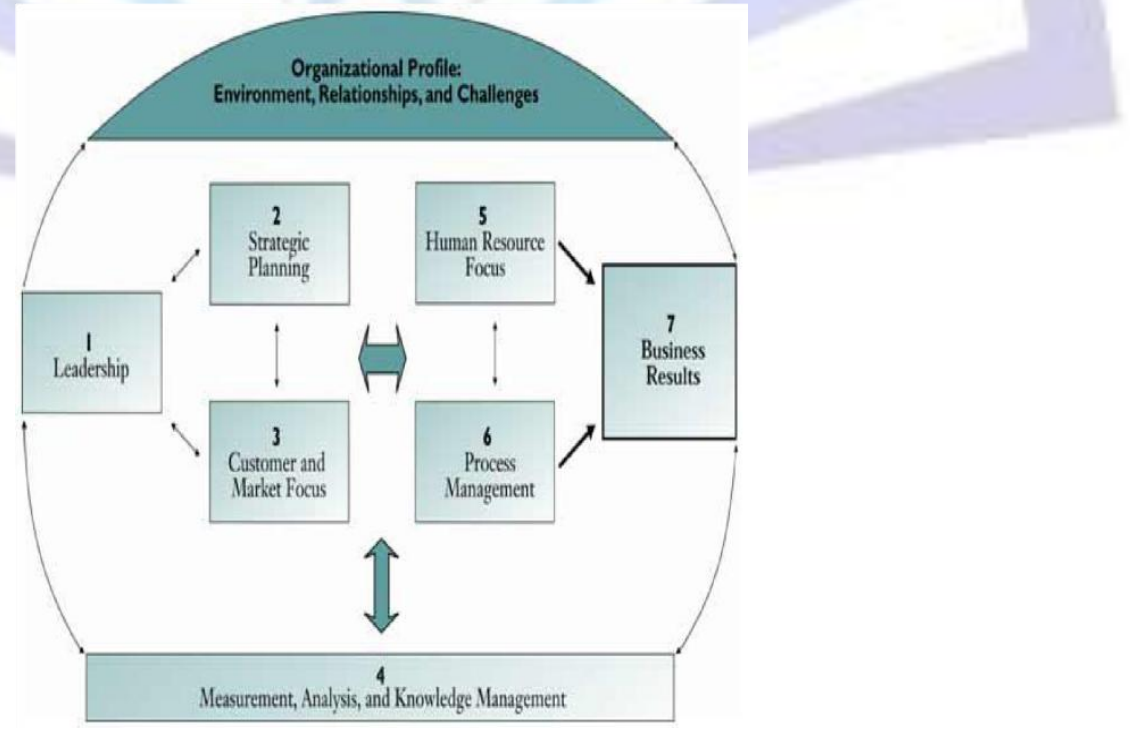

Fig 2. Baldrige Model 
The questions worked in sync to form a distinctive and integrated framework for performance management. By When the questions are answered:

- $\quad$ strategic goals can be achieved

- $\quad$ effectiveness, communication and productivity can be improved

- $\quad$ opportunities and strengths can be identified for improvement; and

- $\quad$ resources can be aligned;

This would result in

- Delivery of value that is always improving to the stakeholders, customers and students, that in turn improves sustainability of the organizational.

- Improvement of the overall capability and effectiveness of the Organization.

- Learning and improving by the Organization.

- Workforce members learn and grow.

While in the paper titled "Introduction and Implementation of TQM (Total quality Management)" - 2010 Khurram Hashmi argues that TQM is primarily related to the continual improvement in all aspects of work that ranges from decision making, executive tasks or strategic planning. He states that TQM's critical principles are:

1. Customer focus:

- $\quad$ Standards driven by customer

- $\quad$ No compromise ever on quality

- Internal customer service relationship and

- $\quad$ Supplier partnership

2. Continuous improvement:

- Improve, Maintain and Attain,standards.

- Process management that is Cross functional

- $\quad$ Excellence team

- $\quad$ Systematic focus and measurement of CONQ

3. Fact based decision making:

- $\quad$ Ford 8D - TOPS

- 7 statistical tool

- $\quad F M E A, D O E$,

- $\quad$ SPC

4. Employee empowerment:

- $\quad$ Excellence teams

- Recognition and Measurement

- $\quad$ Suggestion scheme

- $\quad$ Training

5. Management Commitment:

- $\quad$ Act (revise, , communicate, recognize)

- $\quad$ Check (review)

- Do (participate, support, deploy)

- $\quad$ Plan (direct, drive) 


\section{FINDINGS}

The Baldrige model, the TQM principles, the e-Learning TQM framework having its basis on Kirkpatrick and EFQM model, have one thing in common they aim to achieve the same target even through different approach. Yet, they are all based on the same principles.

If a figure was drawn to depict the aforementioned principle of TQM we would arrive at a figure depicted in Figure 3 , which is similar to what we observe that the Baldrige model and the figure drawn are similar.

\section{CONCLUSION}

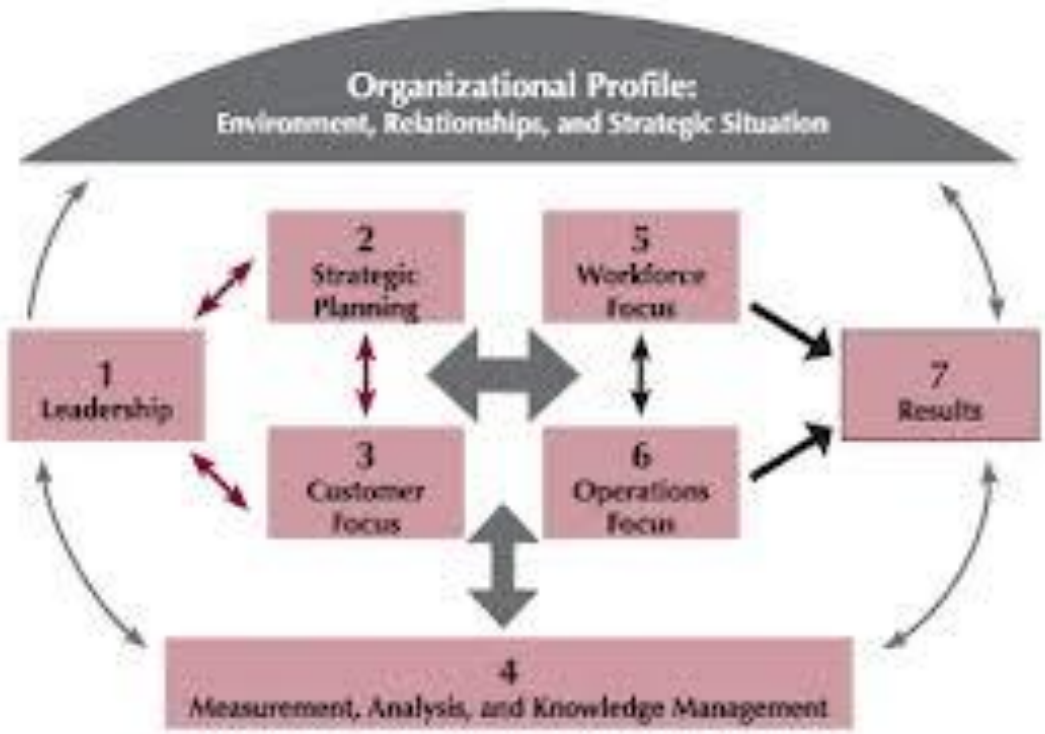

Fig 3. TQM Principles

Even though different researchers advocate different approach for application and implementation of TQM in the various fields they all insist that for any organization to achieve excellence, it is critical for the higher management to be part of the quality process. All of them strongly project the necessity of participation of all employees and functions in the process of improvement. They agree on fact that for continual improvement self evaluation is must.

All the models and theories of TQM have the same end and the same beginning (principles) and they wish to achieve improvement of an organization through continuous effort and team work yet they have different approached to achieve the results.

\section{REFERENCES}

[1] Schreurs, Jeanne. "Total Quality Management Framework for e-learning based on EFQM and Kirkpatrick models." iJET International Journal of Emerging Technologies in Learning (2006): 1-6

[2] Mehortra, Dheeraj. "Applying Total Quality Management in Academic." iSixSigma (2010).

[3] Hashmi, Khurram. "Itroduction and Implementation of Total Quality Management." iSixSigma (2010).

[4] Denis Leonard and Bill Denney. "Aspects of Baldrige - valuable perspective." Quality digest's Quality insider (2007). 